Disclosure of Interest: C. Zhang Grant/research support from: BristolMyers Squibb, Employee of: LIFT1428, Y. Shaw Grant/research support from: Bristol-Myers Squibb, B. Shakley Grant/research support from: Bristol-Myers Squibb, L. Ferri Shareholder of: Bristol-Myers Squibb, Employee of: Bristol-Myers Squibb, K. Michaud Grant/research support from: BristolMyers Squibb, Pfizer and Rheumatology Research Foundation, Employee of: University of Nebraska Medical Centre and National Data Bank for Rheumatic Diseases, D. McDonald Grant/research support from: BristolMyers Squibb, T. Simon Shareholder of: Bristol-Myers Squibb, Employee of: Bristol-Myers Squibb

DOI: 10.1136/annrheumdis-2018-eular.4694

\section{AB1445-HPR PATIENT SATISFACTION IN A RHEUMATOID ARTHRITIS OUTPATIENT CENTRE}

L. Villarreal ${ }^{2}$, D Buitrago-Garcia ${ }^{1}$, F. Rodriguez ${ }^{2}$, I. Mendez $^{2}$, P. Santos-Moreno ${ }^{3}$. ${ }^{1}$ Epidemiology, SIIES; ${ }^{2}$ Health services; ${ }^{3}$ Rheumatology, Biomab, Center For Rheumatoid Arthritis, Bogota, Bogota, Colombia

Background: Patient experience $(\mathrm{PX})$ can be conceptualised as "the sum of all interactions, shaped by an organisation's culture, that influence patient perceptions, across the continuum of care" nowadays patient satisfaction is considered as one of the quality for performance in health systems $\left(.^{1}\right.$ Rheumatology is mainly an outpatient, multidisciplinary medical specialty, therefore care does not stop at the diagnosis it continues during a long-term with frequent monitoring and patient participation. ${ }^{2}$

Objectives: Describe the results of a patient satisfaction survey in a specialised centre in. Colombia during 2017

Methods: In our RA specialised centre during a 12 month period we performed a satisfaction survey in order to evaluate the health services provided. We evaluated the waiting times, timing on attention, appointment assignment, and information provided, the treatment received by the healthcare team, facilities among others. Patients evaluated the services provided in a scale from 1 to 5 were 1 was very bad, 2 bad, 3 regular 4 good and 5 very good. Descriptive epidemiology was performed for each variable presented.

Results: We performed 4756 surveys during 2017, 4550 surveys were completed with a $95 \%$ rate response, out of total $80 \%$ of respondents were female and $20 \%$ male. $80 \%$ of patients reported to receive their appointments on time; regarding the service provided by our health care professionals $99 \%$ of patients understood the indications regarding their treatment, $98 \%$ understood about the administrative procedures to program future appointments and to how to access to their medications, also $98 \%$ had clearly understood the date and time of their consultation (rheumatologist, physical therapist, nutritionist, psychologist, infusion therapy, among others.) The mean score for the overall assessment of the services was 4.2/5.0 (table 1). The average time of stay at our centre was $60 \mathrm{~min} \pm 33$. The main aspects to improve our patient satisfaction were the telephone programming of appointments, and the compliance regarding the delivery of medications.

Abstract AB1445-HPR - Table 1

\begin{tabular}{|c|c|c|}
\hline Question & $\begin{array}{l}\text { MEAN } \\
\text { (SD) }\end{array}$ & $\begin{array}{l}\text { MEDIAN (MIN - } \\
\text { MAX) }\end{array}$ \\
\hline How was the quality of the service provided? & $4.25(0.51)$ & $4(3-5)$ \\
\hline $\begin{array}{l}\text { How was the service provided by our health care } \\
\text { team? }\end{array}$ & $4.31(0.49)$ & $4(1-5)$ \\
\hline How was the service provided $y$ in the waiting room? & $4.27(0.49)$ & $4(1-5)$ \\
\hline Facilities & $4.31(0.49)$ & $4(1-5)$ \\
\hline Overall experience & $4.32(0.53)$ & $4(3-5)$ \\
\hline
\end{tabular}

Conclusions: This survey describes well-functioning multidisciplinary services for all patients who visit to our specialised centre. On the other hand although we found that our patients are highly satisfied, there is a large opportunity to improve our services and generate evidence regarding other aspects that involve the patient's health determinants.

\section{REFERENCES:}

[1] Th VP. Creating the ideal patient experience. Journal of medicine and life. 2016;9(4):380-5

[2] Vare P, Nikiphorou E, Hannonen P, Sokka T. Delivering a one-stop, integrated, and patient-centered service for patients with rheumatic diseases. SAGE open medicine. 2016;4:2050312116654404

Disclosure of Interest: None declared DOI: 10.1136/annrheumdis-2018-eular.6078

\section{AB1446-HPR INVESTIGATION THE EFFECT OF KINESOPHOBIA AND NECK DISABILITY LEVELS ON THE NECK AWARENESS IN CHRONIC NECK PAIN PATIENTS: PILOT STUDY}

D Onan ${ }^{1}$, O. ULGER ${ }^{2} .{ }^{1}$ Physiotheraphy and Rehabilitation; ${ }^{2}$ Health of Sciences, Ankara, Turkey

Background: Chronic neck pain can cause patients to limit their activities due to kinesophobia. Patients may experience more disability during rest because of staying in the same position while restricting their activities, lacking exercise and muscles spasms. For these reasons, they may not be aware of many factors related to the position, movement, and shape of their necks.

Objectives: The aim of this study is to examine the effect of kinesophobia and neck disability levels on neck awareness in individuals with chronic neck pain.

Methods: Forty-two patients who have chronic neck pain and aged 18-65 years were participated in this study. The demographic characteristics of the patients were recorded, kinesiophobia levels with Tampa Kinesiophobia Scale (TKS), neck disability level with Neck Disability Index (NDI) and neck awareness with Fremantle Neck Awareness Questionnaire (FNAQ) were evaluated. Correlation analysis were performed with Pearson correlation coefficients for parametric conditions and the Spearman correlation coefficients for nonparametric conditions.

Results: The mean age of the patients participating in the study was $42,4 \pm 13,47$ years ( 7 men and 36 women). There was a moderate statistically significant positive correlation ( $r=0.462, \quad p<0.01, \quad p=0.002)$ between FNAQ and NDI, indicating that individuals with chronic neck pain had kinesophobia reduced neck awareness. It was found that there was a very good relationship between FNAQ and NDI $(r=0,602, p<0,001)$ and neck awareness decreased as the neck disability level increased. There was a moderately significant relationship between TKS and NDI ( $r=0,567$, $p<0,001$ ), levels of kinesophobia increased as neck disability increased. Conclusions: It has been shown that the high level of kinesophobia and neck disability results in a negative effect on neck awareness and that these three variables are interrelated as a result of our work on neck awareness, which has been rarely studied in the literature. Therefore increasing the activity and movement will reduce the level of neck dis ability and increase awareness. For this reason, patients with chronic neck pain need to be directed in terms of activity and movement.

\section{REFERENCES :}

[1] Hudes, K. (2011) The Tampa Scale of Kinesiophobia and neck pain, disability and range of motion: a narrative review of the literature. The Journal of the Canadian Chiropractic Association, 55 (3), 222-232.

[2] Nederhand, M.J., ljzerman, M.J., Hermens, H.J., Turk, D.C.,Zilvold, G (2004) Predictive value of fear avoidance in developing chronic neck pain disability: consequences for clinical decision making. Arch Phys Med Rehabil, 85 (3), 496-501.

[3] Dragesund, T., Ljunggren, A.E., Kvåle, A.,Strand, L.I. (2010) Body Awareness Rating Questionnaire-Development of a self-administered questionnaire for patients with long-lasting musculoskeletal and psychosomatic disorders. Advances in Physiotherapy, 12 (2), 87-94.

Disclosure of Interest: None declared

DOI: 10.1136/annrheumdis-2018-eular.2601

\section{AB1447-HPR BIOPSYCHOSOCIAL STATUS OF JIA PATIENTS: PERSPECTIVES OF DAILY LIVING ACTIVITIES, DISEASE} ACTIVITY AND FAMILY IMPACT

E Ünal ${ }^{1}$, E.D. Batu Akal ${ }^{2}$, E.H. Sönmez ${ }^{3}$, Z.S. Arıcı ${ }^{4}$, P. Kısacık ${ }^{1}$, G. Arın ${ }^{1}$, N. B. Karaca ${ }^{1}$, D. Aydın Haklı ${ }^{5}$, R. Alpar ${ }^{5}$, Y. Bilginer ${ }^{3}$, S. Özen ${ }^{3} .{ }^{1}$ Department of Physiotherapy and Rehabilitation, Hacettepe University Faculty of Health Sciences; ${ }^{2}$ Ankara Training and Research Hospital; ${ }^{3}$ Department of Pediatrics-

Rheumatology, Hacettepe University Faculty of Medicine, Ankara; ${ }^{4}$ Sanlıurfa Training and Research Hospital, Şanlıurfa; ${ }^{5}$ Department of Biostatistics, Hacettepe University Faculty of Medicine, Ankara, Turkey

Background: Juvenile Idiopathic Arthritis $(\mathrm{JIA})$ is the most frequen chronic rheumatic disease during childhood. It can result in disabilities, loss of quality of life and mood changes. ${ }^{1}$ Furthermore, literature reviewing the effects of arthritis on children and family is inonsistent, with studies showing significant difference or not, compared to healthy children. ${ }^{2}$ Objectives: The purpose of this study is to present results regarding the functional status, psychosocial status and disease activity of children with JIA and their effects on the child's family. The second aim is to present the correlations between these parameters. 